\title{
Study on suitability of compact disc on food preservation
}

\author{
Gitasree Goswami, Sanghamitra Mohapatra and Anita Singh
}

\begin{abstract}
The present research entitled "study on suitability of compact disc on food preservation" was undertaken with the objectives to collect relevant material and develop a $\mathrm{CD}$ on food preservation and to assess the effectiveness of the developed CD. The script of the documentary on food preservation was written in Hindi language so that villagers could be benefited like other respondents (staffs and students). According to the story board clippings for the CD were shoot. Voiceover on food preservation was done in studio after the shooting process and Cyber link power director software was used during the editing process of documentary. The study was conducted during the year 2016 in Allahabad district of Uttar Pradesh. A close ended evaluation schedule was prepared to evaluate the developed compact disc. Sixty respondents were selected purposively for the evaluation of the developed compact disc. Data was analyzed by using suitable statistical tools like frequency, percentage and one way ANOVA. One way ANOVA was used to find out the effectiveness of the CD. Ninety per cents of staffs and students were aware about the parameters of the CD and less by the villagers (70\%). The $\mathrm{CD}$ parameters were divided into six numbers, title of the $\mathrm{CD}$, duration, quality of voice, quality of picture, digital effects and subject matter of the CD. From the tabulated value (3.162), overall results for six parameters were found. The first parameter, title of the $\mathrm{CD}$ found significant result with calculated value 10.92. Likewise for duration and digital effect parameters, results were found non-significant with calculated values 0.64 and 1.19 , respectively, which were lower than tabulated value of $\mathrm{f}$ (3.162). For parameters quality of voice and quality of picture, results were found significant with calculated values 6.45 and 14.35 , respectively. The last parameter was subject matter, in which result was found significant with calculated value 3.88. The cost of the compact disc on food preservation is Rs. 135.00 per CD.
\end{abstract}

Key Words : Compact disc, Food preservation, Evaluation

How to cite this article : Goswami, Gitasree, Mohapatra, Sanghamitra and Singh, Anita (2017). Study on suitability of compact disc on food preservation. Food Sci. Res. J., 8(2): 249-253, DOI : 10.15740/HAS/FSRJ/8.2/249-253. 